\title{
Manajemen Asuhan Kebidanan Antenatal pada Ibu dengan Masalah Plasenta Previa Disertai Anemia di RSUD Syekh Yusuf Gowa Tanggal 02-04 Agustus 2018
}

\author{
${ }^{1}$ Serli, ${ }^{2}$ Anieq, ${ }^{3}$ Nadyah
}

\begin{abstract}
ABSTRAK
Plasenta previa adalah keadaan dimana plasenta berimplantasi pada tempat abnormal, yaitu pada segmen bawah rahim sehingga menutupi sebagian atau seluruh ostium uteri internal. Dari seluruh kasus perdarahan antepartum plasenta previa merupakan penyebab terbanyak. Oleh karena itu, pada kejadian perdarahan atepartum, kemungkinan plasenta previa harus dipikirkan terlebih dahulu karena darah yang keluar terus-menerus bisa mengakibatkan ibu anemia bahkan mengalami syok hingga kematian. Studi ini merupakan laporan kasus dari seorang ibu hamil, 35 tahun, G3P2A0, 26-27 minggu, datang dengan keluhan keluar darah pervaginam tanpa disertai rasa nyeri. Pada pemeriksaan fisik obstetrik, didapatkan bahwa hasil inspeksi terdapat pengeluaran darah pervaginam, hasil USG dan pemeriksaan laboratorium didapatkan plasenta menutupi seluruh jalan lahir serta mengalami anemia ringan ( $\mathrm{Hb}: 10 \mathrm{gr} \%$ ). Oleh karena itu, pasien ini didiagnosis dengan plasenta previa totalis disertai anemia ringan. Penatalaksanaan pasien ini yaitu dibutuhkan penanganan ekspektatif
\end{abstract}

*UIN Alauddin Makassar

\section{PENDAHULUAN}

Angka kematian ibu (AKI) di Indonesia masih merupakan masalah yang menjadi prioritas di bidang kesehatan. AKI Di samping menunjukan derajat kesehatan masyarakat, juga dapat menggambarkan tingkat kesejahteraan masyarakat dan kualitas pelayanan kesehatan. Salah satu penyebab langsung kematian ibu adalah anemia dan perdarahan. Dimana perdarahan ini terkadang disebakan oleh Plasenta previa

Plasenta previa adalah implantasi plasenta pada atau disekitar os serviks internal. Insiden plasen ta previa diperkirakan 1 dalam 200 kehamilan (Mangkuji dkk, 2013 :107). Plasenta previa adalah plasenta yang letaknya abnormal yaitu pada segmen bawah rahim sehingga menutupi sebagian atau seluruh ostium internum (Sujiyatini, 2009 :69).

Anemia merupakan masalah kesehatan masyarakat terbesar di dunia baik pada usia dini, remaja, dewasa, ibu hamil sekalipun karena pada ibuhamil jumlah zat besi dan vitamin yang diperlukan akan lebih dari jumlah sebelum dia hamil karena itu akan dipergunakan untuk membuat haemoglobin, begitu juga dengan jumlah darah akan meningkat menjadi 20\%-30\% lebih banyak dari sebelum dia hamil karena ibu akan membagi jumlah darah dan 
zat besinya tersebut kepada janinnya. Anemia dalam kehamilan tidak bias dipisahkan oleh perubahan fisiologi yang terjadi selama proses kehamilan, umurjanin, dan kondisi ibu sebelum hamil (Noverstiti, 2012; Willy Astriana, 2017).

World Health Organization (WHO) memperkirakan terdapat 216/100.000 kelahiran hidup akibat komplikasi kehamilan dan persalinan tahun 2015. Jumlah total kematian ibu diperkirakan mencapai 303.000 kematian diseluruh dunia. Maternal Mortality Rate (MMR) di negara berkembang mencapai 239/100.000 kelahiran hidup, 20 kali dibandingkan negara maju. Dapat diperkirakan pada tahun 2015, negara berkembang menyumbang sekitar 90\% atau 302.000 dari seluruh total kematian ibu dan Indonesia merupakan salah satu negara berkembang yang menyumbangkan angka tertinggi pada kematian ibu di dunia. WHO memperkirakan di Indonesia terdapat 126/100.000 kelahiran hidup dengan jumlah kematian ibu 6400 pada tahun 2015

Angka anemia kehamilan di Indonesia menunjukan nilai yang cukup tinggi. Hoo Swie Tjiong dalam Manuaba menemukan angka anemia kehamilan 3,8\% pada trimester I, 13,6\% trimester II, dan $24,8 \%$ pada trimester III, sedangkan menurut Saifudin menyebutkan angka anemia secara nasional untuk ibu hamil mencapai angka 63,5\% (2) (Fatimah dan susi, 2015 $: 135)$.

AKI adalah kematian perempuan pada saat hamil atau kematian dalam kurun waktu 42 hari sejak terminasi kehamilan tanpa memandang lamanya kehamilan, yakni kematian yang disebabkan karena kehamilannya atau penanganannya, tetapi bukan karena sebab-sebab lain seperti kecelakaan dan terjatuh. Angka kematian ibu, bayi dan balita di Indonesia masih cukup tinggi. Tujuan pembangunan MIllenium Development Goals (MDGs) 2000-2015 dan sekarang dilanjutkan dengan Sustainable Development Goals (SDGs) 2015-2030 berkomitmen untuk menurunkan status kesehatan ibu hamil, bersalin dan nifas (Profil Kesehatan Kota Makassar Tahun 2016).

Di Kota Makassar, AKI maternal mengalami fluktuasi selama 3 tahun terakhir yaitu pada tahun 2016 sebanyak 6 kematian ibu dari 25.614 kelahiran hidup (AKI: 23,42 /100.000 KH) sedangkan pada 2015 sebanyak 5 kematian ibu dari 25.181 kelahiran hidup (AKI: 19,86/100.000 KH). Tahun 2014 sebanyak 5 kematian ibu dari 24.590 kelahiran hidup (AKI: 20,33/100.000KH) (Profil Kesehatan Kota Makassar Tahun 2016). 
Anemia dapat disebabkan oleh beberapa hal diantaranya perdarahan pervaginam, pengaruh mual saat sedang hamil, kebutuhan akan zat besi yang bertambah karena pertumbuhan janin, kurangnya cadangan zat besi yang dimiliki oleh ibu hamil akibat menstruasi atau persalinan sebelumnya. Apabila kita telah mengetahui penyebab dari anemia itu sendiri maka perlu diwaspadai gejala dari anemia itu yakni jantung berdebar-debar lebih dari batas normalnya, wajah terlihat pucat, cepat merasa lelah, nafsu makan berkurang, sering merasakan sakit kepala dan cepat merasa letih, kebugaran tubuh menurun.

Plasenta previa dapat mengakibatkan terjadinya anemia bahkan syok, terjadi robekan pada serviks dan segmen bawah rahim yang rapuh, bahkan infeksi pada perdarahan yang banyak, sedangkan pada janin dapat terjadi kelainan letak janin, prematuritas, morbiditas dan mortalitas yang tinggi, asfiksia intrauterin sampai dengan kematian.

Data di ruangan KIA RSUD (Rumah SakitUmum Daerah) Syekh Yusuf Gowa tercatat pasien dengan anemia dan plasenta previa yang didapatkan di tahun 2018 di bulan januari 1 orang mengalami partus pervaginam+anemia di kamar nifas dari 322 pasien yang ada, di bulan februari terdapat 2 orang yang mengalami anemia di kamar bersalin dari 275 pasien yang ada dan poli KIA terdapat 1 orang mengalami anemia dari 36 pasien yang ada dan 1 orang yang mengalami plasenta previa di kamar bersalin dari 275 pasienygada, di bulan maret terdapat 2 orang yang mengalami plasenta previa totalis di poli KIA dari 41 pasien yang ada dan di bulan juni terdapat 2 pasien yang mengalami plasenta totalis disertai anemia di kamar bersalin (Data Register Rawat Inap dan Rawat Jalan RSUD Syekh Yusuf).

Beda halnya dengan data dari RSUD Labuang Baji, dimana di bulanjanuariterdapat 1 orang anemia dari 13 pasien yang ada, 7 orang yang mengalami plasenta akreta dari 9 pasien yang ada, di bulan februari terdapat 3 orang anemia dari 6 pasien yang ada, 2 orang yang mengalami plasenta previa totalis disertai anemia, 20 orang mengalami plasenta akreta dari 24 pasien yang ada, di bulan maret terdapat 3 pasien anemia dari 7 pasien yang ada, 15 pasien yang mengalami plasenta akreta.

Berdasarkan data di atas peneliti tertarik ingin mengkaji mendalami dan mencoba menerapkan asuhan kebidanan pada ibu hamil dengan masalah Plasenta Previa disertai Anemia di RSUD Syekh Yusuf diharapkan dapat lebih membantu menurunkan angka kematian ibu baik di SulSel, Indonesia maupun dunia. 


\section{METODE PENELITIAN}

Jenis penelitian ini adalah studi kasus dengan pendekatan Manajemen Asuhan Kebidanan sesuai dengan 7 langkah Varney dan pendokumentasian dalam bentuk Penatalaksanaan Asuhan dilakukan dengan pemberian asuhan yang sesuai dengan standar operasional prosedur pada kasus yang diteliti

\section{HASIL PENELITIAN}

Penelitian ini dilakukan di RSUD Syekh Yusuf Gowa mulai tanggal 02-04 Agustus 2018. Peneliti melakukan pendekatan Manajemen Asuhan Kebidanan yang terdiri dari 7 langkah Varney. Dimulai dari langkah pertama, peneliti melakukan pengkajian data dasar dimulai dari pengkajian identitas, subjektif, data objektif. Pada kunjungan itu didapatkan ibu mengeluh keluar darah dari jalan lahir secara tiba-tiba dengan darah warna merah segar, ada gumpalan, tanpa disertai rasa nyeri dan mengalami sedikit pusing. Ibu merasa cemas karena ini perdarahan yang terjadi untuk kedua kalinya.

Pada langkah kedua, peneliti mengidentifikasi diagnosa atau masalah aktual. Pada kasus ibu dengan plasenta previa totalis di ruang kebidanan, diagnosis yang dapat ditegakkan yaitu: G3P2A0, gestasi 27 minggu 5 hari, situs memanjang, tunggal, hidup, intrauterin, keadaan janin baik, ibu dengan plasenta previa totalis

Sedangkan masalah yang dialami oleh ibu adalah anemia ringan yang ditandai dengan ibu mengeluh sedikit pusing konjungtiva tampak pucat, $\mathrm{Hb}$ : $10 \mathrm{gr} \%$.

Pada langkah ketiga, peneliti mengidentifikasi diagnosa atau masalah potensial. Pada kasus ibu, adapun masalah potensial tersebut adalah antisipasi terjadinya perdarahan antepartum. Pada langkah keempat, peneliti mengidentifikasi perlunya tindakan segera oleh bidan atau dokter. Pada kasus ibu hamil dengan anemia diagnose potensial yang mungkin terjadi adalah persalinan lama, terjadi infeksi, perdarahan antepartum, pengeluaran Asi kurang. Sedangkan pada kasus plasenta previa diagnosa potensial yang mungkin terjadi adalah syok sebelum atau selama persalinan, bahkan preterm (sebelum kehamilan mencapai 37 minggu) yang mengakibatkan gawat janin.

Bila memungkinakan dilakukan pencegahan. Bidan diharapkan dapat waspada dan bersiap-siap. 
Pada langkah kelima, peneliti merencanakan rencana asuhan. Kasus ibu dengan plasenta previa gestasi kurang dari 37 minggu, keadaan umum ibu cukup baik, dan janin masih hidup, maka dilakukan terapi ekspektatif yaitu rawat inap, tirah baring, perbaiki anemia dan observasi, DJJ TTV, serta perdarahan yang terjadi.

Pada langkah keenam, peneliti mengimplementasikan rencana asuhan yang telah disusun. Pada kasus ibu asuhan diberikan sejak hari pertama yaitu tanggal 02 Agustus 2018 hingga hari ketiga yaitu tanggal 04 Agustus 2018 dengan total 3 hari rawat inap. Pada langkah ini peneliti tidak menemukan hambatan yang berarti dalam memberikan asuhan kebidanan karena seluruh tindakan yang dilakukan telah mengarah dan sesuai dengan apa yang dibutuhkan pasien. Serta pasien dan keluarga dapat bekerjasama dengan baik dalam pelaksanaan pemberian asuhan kebidanan. Pada langkah ketujuh, evaluasi dari hasil asuhan yang telah diberikan kepada ibu. Pada kasus ibu dengan plasenta previa totalis dengan anemia ringan hasil yang ditemukan perawatan ibu berlangsung dengan baik dengan keadaan janin baik dan masih bias dipertahankan.

\section{PEMBAHASAN}

Berdasarkan hasil pengkajian pada ibu didapatkan hasil anamnesis yang menunjukkan bahwa diagnosis G3P2A0, gestasi 27 minggu 5 hari, situs memanjang, tunggal, hidup, intrauterin, keadaan janin baik, ibu dengan plasenta previa totalis. Hasil yang diperoleh dari kasus ibu yaitu pada langkah pertama, ibu mengutarakan semua keluhan yang dialaminya dan tidak mengalami hambatan dalam proses pengkajian, sebagai seorang bidan kita harus tetap memberikan dukungan psikologis kepada ibu dan keluarga untuk tetap tenang dan berdo'a kepada Allah SWT, dan berdzikir untuk kesehatan dan keselamatan ibu maupun janinnya. Ditemukan pula pada teori yaitu plasenta previa terjadi setelah kehamilan 22 minggu yang dimana letaknya abnormal atau pada segmen bawah uterus sehingga menutupi sebagian atau seluruh pembukaan jalan lahir.Sifat perdarahannya adalah tanpa sebab (causeless), tanpa nyeri (Ipainless), dan berulang (recurrent) (Masriroh, 2013). Pada langkah kedua, dengan keluhan yang telah diutarakan dan pemeriksaan yang telah dilakukan didapat ibu mengalami anemia ringa dengan $\mathrm{Hb} 10$ gr\%. Sebagai bidan harus selalu meyakinkan pasien bahwa dibalik kesulitan pasti ada jalan. Anemia adalah pengurangan jumlah sel darah merah, kuantitas hemoglobin, dan volume pada sel darah merah (hematokrit) per $100 \mathrm{ml}$ darah. Anemia dalam kehamilan adalah kondisi ibu dengan kadar nilai hemoglobin dibawah 11 gr\% 
pada trimester $1 \& 3$, atau kadar nilai hemoglobin kurang dari $10,5 \operatorname{gr} \%$ pada trimester 2 (Darmawansyih, 2014 :181). Langkah ketiga, didapatkan perdarahan antepartum yang dimana bidan harus melakukan pendekatan yang baik kepada klien untuk selalu menyarankan pasien untuk tetap tenang dan banyak berdo'a karena ditakutkan terjadi syok hipovolemik. semua kasus dugaan plasenta previa harus dirawat di rumah sakit rujukan. Pemeriksaan melalui vaginal atau rectal harus dihindari untuk mencegah perdarahan lebih lanjut. Beberapa diagnosis banding untuk plasenta previa adalah solusio plasenta dan plasenta sirkumvalata (Fadlu, Feryanto, 2011: 64). Pada langkah keempat, dilakukan kolaborasi dengan dokter obgyn agar segera dilakukan USG untuk melihat kondisi janinnya. Beri tahu ibu agar selalu berdzikir dan percaya bahwa Allah akan member jalan yang terbaik. Pada langkah kelima, tidak terjadi hambatan dalam pemberian informasi kepada pasien dan keluarga bahwa pasien harus dirawat inap untuk dilakukan pengawasan baik pada ibu maupun janin. Langkah keenam, tidak terjadi hambatan karena telah diberikan asuhan selama 3 hari sesuai dengan yang dibutuhkan pasien serta selalu mengingatkan pasien untuk tetap berdo'a akan keselaman dirinya maupun janinnya. Langkah ketujuh adalah evaluasi dari semua langkah yang telah dilakukan dimana ibu dengan plasenta previa totalis disertai anemia ringan telah diberikan perawatan secara optimal dengan hasil keadaan ibu dan janin dalam keadaan baik.

\section{KESIMPULAN DAN SARAN}

\section{A. KESIMPULAN}

Setelah mempelajari tinjauan pustaka dan pengalaman langsung dari lahan praktek melalui studi kasus, serta membandingkan antara teori dengan praktek berdasarkan hasil pengkajian mengenai manajemen asuhan kebidanan pada ibu gestasi 27 minggu 5 hari dengan plasenta previa totalis disertai anemia ringan di RSUD Syekh Yusuf Gowa, maka dapat ditarik kesimpulan bahwa:

1. Plasenta previa adalah plasenta yang letaknya abnormal, yaitu pada segmen bawah uterus, sehingga dapat menutupi sebagian atau seluruh pembukaan jalan lahir. Pada keadaan normal, plasenta terletak dibagian atas uterus.

2. Perdarahan yang terjadi pada ibu di sebabkan karena plasenta berimplantasi pada segmen bawah uterus, tepatnya menutupijalanlahir, sehingga terjadi pengeluaran darah segar pervaginam yang disertai gumpalan tanpa menimbulkan rasa nyeri. 
3. Pengkajian dilakukan dengan menggunakan Teknik 7 langkah varney. Selama pengakjian mulai tanggal, diperoleh dari hasil evaluasi asuhan kebidanan yaitu perdarahan yang dialami oleh ibu sudah berhenti, kecemasan teratasi, anemia ringan teratasi ditandai dengan konjungtiva sudah agak merah muda dan kadar $\mathrm{Hb}: 10,5$ gr\%.

4. Pendokumentasian yang dilakukan pada ibu mengacu pada manajemen asuhan kebidanan sesuai dengan pola fikir varney.

5. Dalam upaya penerapan dokumentasi kebidanan penting untuk dilaksanakan, karena merupakan alat pembuktian untuk pertanggung jawaban bidan terhadap asuhan kebidanan yang telah diberikan kepada klien.

6. Perdarahan yang tidak mendapatkan penanganan dengan baik dapat membahayakan keselamatan ibu dan janinnya

\section{B. SARAN}

1. Terhadap Klien

a. Menganjurkan kepada klien agar rajin memeriksakan kehamilannya di RS terdekat yang memiliki fasilitas lengkap apabila terjadi komplikasi yang dapat membahayakan klien.

b. Keterlibatan anggota keluarga sangat diperlukan untuk lebih memfokuskan perhatian terhadap klien.

2. Terhadap Bidan

a. Dalamme laksanakantugassebagaibidan, diharapkan agar dapat memberikan pelayanan yang professional sesuai dengan kebutuhan akan masalah yang sedang dialami oleh klien.

b. Sebagai seorang bidan, diharapkan dapat mengetahui secara pasti batas wewenang seorang bidan, serta tidak melakukan praktek-praktek yang dapat merugikan klien ataupun keluarga klien, agar tercapai tujuan yang diinginkan, sehingga dapat memberikan kepuasaan kepada klien akan pelayanan yang telah diberikan

\section{Terhadap Institusi}

Diharapkan dapat meningkatkan kinerja pembelajaran terhadap mahasiswi kebidanan baik teori maupun praktek, sehingga setiap tahunnya dapat melahirkan alumni kebidanan yang professional, intelektual, dan terampil dalam bidang kebidanan, khususnya penerapan manejemen asuhan kebidanan dalam rangka pemecahan 
masalah yang dialami oleh klien, sehingga dapat menciptakan kepuasan terhadap klien yang membutuhkan pelayanan seorang bidan

\section{DAFTAR PUSTAKA}

Astriana, Willy "Kejadian Anemia pada Ibu Hamil Ditinjau dari Paritas dan Usia”, Jurnal Ilmu Kesehatan, Vol 2, No 2, 2017

Darmawansyih. Penyakit Kronik dalam Kehamilan. Makassar: Alauddin University Press, 2014

Dinas Kesehatan Provinsi Sulawesi Selatan, Profil Kesehatan Provinsi Sulawesi Selatan, Makassar: SIK, 2016

Fadlun, Feryanto, Achmad. Asuhan Kebidanan Patologi. Jakarta: Salemba Medika, 2011

Mangkuji, Betty, dkk. Asuhan Kebidanan 7 Langkah SOAP. Jakarta: EGC, 2013

Masriroh. Keperawatan Obstetri dan Ginekologi. Yogyakarta: Imperium, 2013

Proverawati, Atikah. Anemia Dan Anemia Kehamilan. Yogyakarta: Nuha Medika 2011

Tartwoto dan Wasnidar. Buku Saku Anemia Pada Ibu Hamil Konsep Dan Pentalaksanaan. Jakarta: Trans Info Media, 2013

World Health Organization, dkk. Buku Saku Pelayanan Kesehatan Ibu di Fasilitas Kesehatan Dasar dan Rujukan. Jakarta: UNFPA, Unicef, USAID, 2013

Yeni, dkk "Plasenta Previa Totalis Pada Primigravida", Jurnal Kedokteran Syiah Kuala, Vol 17, No 1, 2017

Yeyeh Ai Rukiyah, Yulianti, Lia. Asuhan Kebidanan Patologi 4. Jakarta: CV. Trans Info Media, 2013 